Review

\title{
What Activities Count as Active Aging? The Challenge of Classifying Diversity
}

Feliciano Villar ${ }^{*}$, Montserrat Celdrán, Rodrigo Serrat, Valentina Cannella

Department of Cognition, Development and Educational Psychology, University of Barcelona, Passeig de la Vall d'Hebron 171, Barcelona 08035, Spain; E-Mails: fvillar@ub.edu; mceldran@ub.edu; rserrat@ub.edu; cannellavalentina@ub.edu

* Correspondence: Feliciano Villar; E-Mail: fvillar@ub.edu

Academic Editor: Lisa Hollis-Sawyer

Special Issue: Got Aging? Examining Later-life Development from a Positive Aging Perspective

\section{OBM Geriatrics}

2018, volume 2 , issue 4

doi:10.21926/obm.geriatr.1804027
Received: November 07, 2018

Accepted: December 19, 2018

Published: December 26, 2018

\begin{abstract}
Active aging is a concept used to describe and promote lifestyles that contribute to a healthy aging process. However, these lifestyles vary widely, and the concept of active aging encompasses many activities. This paper considers two axes to classify the range of activities that can contribute to active aging: the resources needed to carry out such activities (low and high-resource needs) and the main orientation of the activities (self-oriented vs. activity with others). To illustrate this classification, three types of participation were analyzed, including in leisure activities, high-demand sports, and political organizations. The presented discussion compares these three activities, reveals challenges for future research using this new classification, highlights the practical implications of diversity when promoting forms of active aging.
\end{abstract}

\section{Keywords}

Active aging; activities; classifying diversity

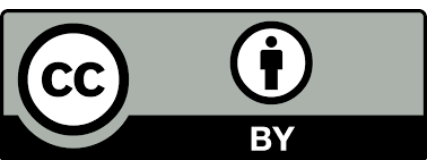

(C) 2018 by the author. This is an open access article distributed under the conditions of the Creative Commons by Attribution License, which permits unrestricted use, distribution, and reproduction in any medium or format, provided the original work is correctly cited. 


\section{Introduction}

In recent decades, gerontology researchers and policymakers responsible for aging issues have focused on formulating a gold standard that ensures increasing numbers of older people have access to a successful and healthy aging path. This interest has arisen primarily due to the population aging phenomenon. This emphasis on 'aging well' contrasts with the traditional view of aging, which is commonly linked to loss and decline by aiming to redefine older people. This redirection views elders as a resource for their families and the communities in which they live rather than as a burden to society.

This interest has given rise to concepts that help capture such a positive view of aging and attempt to define what is meant by the phrase 'aging well.' Thus, terms such as productive aging, healthy aging, successful aging, and active aging [1, 2], sometimes with partially overlapping meanings and interchangeable uses [3], have been coined in an effort to bring about this new aging paradigm.

The concept of active aging has gained popularity among gerontological researchers and social policymakers due to two main reasons. First, the concept of active aging, which the World Health Organization (WHO) [4] defines as "the process of optimizing opportunities for health, participation and security in order to enhance quality of life as people age," is broad and inclusive. It emphasizes both individualistic aspects, such as health and well-being, and social and communitarian aspects, such as participation and the design of secure environments. As some authors suggest, the concept of active aging is also ambiguous and open enough to attract both policymakers and scholars from different academic disciplines [5]. Thus, an active aging advocate could claim that this concept overlaps with and encompasses others aspects like healthy and productive aging. Second, active aging is the conceptual framework chosen by political actors to promote the successful-aging paradigm. International organizations, such as the European Union [6], and national and local institutions have adopted active aging as a guideline to design policies on aging. Similarly, the WHO recently confirmed the conceptual validity of active aging as a response to coping with the challenges of longevity from individual, national, and global standpoints $[7,8]$.

Despite the wide range of standpoints, active aging is not exempt from polemics and criticism [9]. One of the main criticisms relates to the criteria used to include (and discard) certain activities in the definition of active aging, based on the different effects they may have on personal and social development [10].

Thus, the aim of this work was to clarify and determine a basis to classify the broad range of activities included within the definition of active aging, as a multidimensional concept. Discussions are also provided on the prototypical activities corresponding to each type of active aging and highlight the fact that not all activities of older persons have the same value, which could help guide and prioritize social policies in this field.

\section{Diversity in Active Aging}

Although the concept of active aging has become increasingly important in the field of gerontology from both a research and social policy perspective, there is still limited research on the type of activities that should be included in a so-called 'active' life of older persons. Most of 
the time, such discussions have been implicit, or an assumption has been made that active aging involves one or more key activities.

Some authors [9] have suggested that, when explicitly mentioned, such active aging activities tend to be selected primarily for their social and economic impact. For instance, the most ambitious proposal for measuring the extent to which active aging is present in different communities and countries, known as the 'Active Aging Index' [11], emphasizes participation in the labor market as a fundamental factor. In addition, two out of the four social participation indicators proposed by the Active Aging Index are associated with caring for relatives, an activity that also has an important economic impact [12].

One way to offer a more inclusive and complex view of active aging that encompasses more diverse forms of successful aging is to consider activities that have psychological and social implications instead of, or in addition to, productive value. In that regard, some leisure activities, particularly those involving a certain intellectual or physical effort [13], can also be considered as key components in an active aging lifestyle. Similarly, learning activities [14], volunteering [15], and political activism [16] may also be good candidates for inclusion in this more extensive definition of active aging.

Broadening the active aging model to include activities beyond those that are strictly related to production runs the risk that all active aging activities will be assumed to function in the same way or have the exact same value. In fact, each activity may have different impacts on different people, and their individual and social implications may also be highly diverse. Thus, an expanded definition of active aging should go hand in hand with an effort to classify such activities and determine their similarities and differences. In that regard, some researchers have tried to classify activities that potentially contribute to active aging according to diverse criteria, such as the degree to which they benefit others, the level of commitment and effort required, and the resources needed to carry out the activity [5, 17-19].

In our opinion, active aging activities may be classified according to two axes. First, the quantity and quality of resources required to undertake them, in terms of time, expertise, social capital, and commitment. The second is the orientation of the activity, i.e., whether it is self-oriented or includes activities with others. These two aspects can be further divided into the following prototypical active aging activities:

(1) Self-oriented activities typically involving a low level of resources might include a wide range of recreational activities, whether organized by the community or senior centers or carried out by individuals on their own. These usually range from artistic activities to health- and wellbeing-related activities, and social and cultural activities in a broad sense.

(2) Self-oriented activities involving a high level of resources include those that are intellectual in nature (e.g., university programs for older people) and activities that require the mobilization of physical resources (e.g., moderate or intensive sports such as cycling, swimming, and athletics).

(3) A third group of activities is oriented towards others and involves a low level of resources, which include activities that are undertaken within a family context (e.g., auxiliary care for grandchildren) and are community-based (e.g., specific and low-skilled volunteering tasks).

(4) Lastly, other-oriented activities that involve a high degree of expertise and resources include those carried out within a family context (e.g., intensive care for grandchildren or dependent relatives), in community settings (e.g., volunteering activities involving a great deal of 
commitment and highly specialized tasks), and political activities, such as participation in political parties and trade unions.

We think that such a classification system may contribute towards the organization of different types of active aging activities despite its drawbacks, such as the difficulty of identifying criteria to differentiate between 'low' and 'high' levels of resources and certain activities that could be both self- and other-oriented. In addition, this system could be used as a tool to identify key aspects that can be used to compare activities. Such comparisons could make it possible to recognize common patterns, differences in functions, and predictive factors. From the latter, it could be determined if there are different styles of active aging, common predictors regardless of the nature of the activity, or if participation in one or another depends on specific determinants. Associated benefits could also be identified, including the indication of positive consequences for both the individual and the community the same regardless of the activity, or if such benefits are activity-specific. Therefore, comparisons based on key aspects may have important implications for determining, selecting, and prioritizing aging-related policies.

In an attempt to answer these concerns, and due to the space limitations, we compared three prototypical active aging activities among many others that could be included in each category of the classification. First, participation in leisure activities was organized and conducted by senior centers (a low-resource activity that is mainly self-oriented). Second, formal participation was analyzed in high-intensity sports (a high-resource, self-oriented activity). Finally, we examined participation in political organizations (a high-resource, other-oriented activity). For all three cases, we chose a formal mode of participation (i.e., membership of a formal organization) to make subsequent comparisons between the activities easier to detect.

We were aware that to complete the comparison we would need a fourth activity that is lowresource and other-oriented. For instance, some activities performed under the umbrella of voluntary organizations could provide good examples for this category. Unfortunately, voluntary activities are very diverse. These include low and high-resource activities that generally are not differentiated in research on aging activities, which increases the difficulty in using them as a single comparison term as were the three other activities.

\section{Leisure as A Form of Active Aging}

Leisure or recreational activities, which are carried out primarily for pleasure, are a good example of self-oriented, low-resource activities. However, leisure includes a wide range of activities performed in different contexts, which makes it difficult to treat it as a unit. To limit such diversity, we only focused on activities performed in senior centers that involve participating in a formal organization that structures and organizes leisure activities.

Attending senior centers is a fairly common practice in many countries. For instance, the Older Americans Act [20] estimates that there are more than 10,000 senior centers in the United States alone. Despite this popularity, little research has been carried out on the activities and relationships that develop in such institutions, older people's involvement in the management of senior centers, and the differences between the activities they promote (despite some exceptions $[21,22])$. 


\subsection{Antecedents}

To understand why older people get involved in leisure activities organized by senior centers, it might be useful to divide antecedent factors into personal resources (health, family, and community responsibilities, skills and competences, self-esteem, emotional resources, etc.) and motivational factors as well as those related to the opportunities provided by a social context or an organization. All these factors can act as both facilitators (when a person has them) and hindrances (when a person lacks them) of activity involvement.

With respect to studies on attendance at senior centers, the most widely examined barriers (rather than facilitator) are organizational and personal resources. In regards to personal resources, two issues stand out: (a) the limited socioeconomic and cultural diversity of older people who attend senior centers, and (b) the challenges posed by the new generation of baby boomers for such centers, which includes the need to adapt to this new cohort of older persons.

As for the limited diversity, available data suggest that senior centers have highly feminized settings [23] that do not mirror the social and cultural community in which they are based (OACC, 2015). Thus, a typical senior is of an advanced age (75 years and older) [20] and lives in an urban setting (more than 100,000 inhabitants) [24]. This characterization limits the inclusion of older people with disabilities [25], cultural diversity [26], and even sexual diversity, since older lesbian, gay, bisexual, and transsexual (LGBT) people rarely attend senior centers [27].

In recent years, it has been argued that the present senior center model might become obsolete, since the new generation of older people may be less interested in attending such agesegregated centers after retirement. The reason for this apparent lack of interest lies in the emergence of new interests and ways of spending leisure time $[23,28]$ and a reluctance to attend a center where they are labeled as 'older people,' a classification that could lead to rejection [29]. However, other authors have pointed out that if senior centers evolve to become 'ageless' institutions, they could restrict activities that attract older people who might struggle to find other leisure options suited to their needs and preferences [30].

With respect to barriers related to organizational issues at senior centers, it has been suggested that it is becoming increasingly difficult to use senior centers as providers of specific, evidencebased programs which aim at improving older people's health and well-being through programs to prevent specific illnesses, health education, and promotion of healthy lifestyles. Such difficulties lie in the low levels of interest among older people who are the target audience for such programs, the rigidity involved in the implementation of programs, and the competence of other types of settings and institutions that offer similar programs [31].

\subsection{Benefits}

Research on the impact of older people's attendance at senior centers has found evidence of a broad range of health-related, psychological, and social benefits. Thus, older people attending senior centers seem to maintain or even improve their health status [32], reduce depressive symptoms [33], reduce stress caused by other activities, such as caring for dependent relatives [34], and increase their social networks and social support [35].

However, some studies that evaluated the impact of attending senior centers have generally failed to identify the specific factors responsible for these positive effects. Such factors could be 
the result of the mere attendance at any institution, whatever the type (since the person is compelled to interact with others rather than staying at home), or alternatively, they could be linked to the activities undertaken in the centers [36]. So far, a limited number of specific activities carried out in senior centers have been evaluated for their impact on participants, which include gardening [32] and intergenerational activities [37]. Yet, it is apparent that further research is needed in this area.

\section{High-Intensity Sport as A Form of Active Aging}

Practicing high-intensity sports, including formal participation in clubs, associations, and federations, is a prototypical example of an activity that involves many resources and has a clear individual orientation.

Research on older persons in high-intensity sports is relatively scarce due to the tendency to underline the recreational and social dimensions of sports in older age, rather than studying the activity in terms of performance and gains [38]. In addition, the number of older people involved in sports is not particularly high. For instance, according to the European Commission (2014) [39], around $8 \%$ of people over the age of 55 in Europe regularly practice a sport. Despite this, some authors define older athletes as the epitome (and an indicator) of successful aging [40], and this recent emphasis of active and healthy aging has contributed to the normalization of adults playing sports later in life [41].

\subsection{Antecedents}

With respect to the factors that account for participation in high-intensity sports, most of the research has focused on determining the motivations and disincentives for older adults to participate.

The motives can be classified into two main groups: intrapersonal and interpersonal [42]. For intrapersonal factors, studies have been conducted on personal attitudes towards sporting practice, knowledge about the benefits involved, enjoyment associated with the recreational nature of sports, relevance of external rewards, and the role played by recognition of athletic success [43]. Other studies have differentiated between competitive and friendly participation and highlight how older athletes are reluctant to admit that they value external rewards and social recognition. This is because most people consider that 'although seniors are competitive, they are not particularly focused on winning' [44], which is an attitude that might help perpetuate negative stereotypes associated with older ages. With respect to interpersonal factors, evidence shows that the encouragement older people receive from relatives and friends [45] and medical advice are motivation to begin, and continue, participating in sports.

As for barriers that hinder participation in high-intensity sporting practice, some authors have underlined the role of a person's life history as a determinant of his or her current involvement. Thus, family and school have been identified as primary socialization contexts that help people interiorize values and habits regarding sporting practice [46].

In addition to factors related to habits and values rooted in one's life history, other variables act as barriers to sporting practice. Socioeconomic status seems to play a key role consider that older people with greater economic resources are more likely to be involved in sporting activities [47, 
48]. Other factors accounting for participation are gender, marital status (widows represent the group least likely to be involved in sports), previous occupation, and education level [49].

Beyond sociodemographic variables, other psychological aspects, such as the belief of being 'too old' to practice a sport, fear of suffering some kind of injury, and viewing oneself as not having 'sporty' attributes [50], could also act as barriers to practicing sport in later life.

Finally, there are also barriers associated with contextual aspects, including a lack of appropriate facilities to practice sports and an absence of nearby affordable alternatives tailored to the specific needs of older people [46].

\subsection{Benefits}

The literature on sports practice by older adults highlights the many physical, psychological, and social benefits. For instance, there is clear evidence $[51,52]$ that cardiovascular health and muscle tone improve with practicing moderate or high-intensity sports in older ages. These benefits, in turn, have a positive impact on the risk of falls, thereby promoting autonomy and reducing the financial and psychosocial burden associated with dependency.

On the downside, practicing high-intensity sports implies a greater risk of injury, pain, and excessive effort [53]. Studies have also shown that some older people who practice high-intensity sports may develop an addiction to exercise, which is associated with a tendency to deny the unavoidable physical decline involved in the aging process [54].

From a psychological point of view, research has focused on analyzing the impact of sporting practice on both emotional and cognitive aspects [53]. With respect to the emotional benefits, mental health, self-confidence, and self-esteem seem to improve with sporting activity. Older people who practice sports also present lower stress and anxiety levels and a reduction in depressive symptoms [55]. Regarding the cognitive benefits, there is some evidence suggesting that cognitive function, in terms of attention, memory, and reaction time, improves in older people who are actively involved in a high-intensity sporting activity [56]. Additionally, practicing a competitive sport may help to distance oneself from age stereotypes of dependence and passivity $[57,58]$.

When a sport is practiced in organized clubs or teams, the benefits for psychological well-being are even greater than when the sport is practiced on an individual basis. The social bonds and support from teammates are likely to account for this improved well-being [43]. Similarly, practicing sports is associated with wider and stronger social networks [59], thereby reducing the odds of being socially isolated in later life.

\section{Political Activism as an Active Aging Activity}

Political participation by older adults is clearly an active aging activity involving others. Despite the fact that some types of political involvement include a low investment of personal resources (e.g., voting and signing petitions), this section focuses on political activities that require a higher investment, such as having a membership with a political organization and social movement activism. The percentage of older people involved in such activities varies widely depending on the country, the specific sample being analyzed, and tool(s) and political situation of data collection, all of which are, all of which are factors that hamper comparison of results. 


\subsection{Antecedents}

With respect to antecedent factors relating to political activism in later life, some studies have addressed the role played by personal resources, motivational influences, and factors related to the opportunities offered by the political participation of older people.

Regarding personal resources, it seems that older people who participate in politics have higher education and income levels than those who do not [16]. In addition, older activists tend to participate more in other active aging activities and have more associative links, wider social networks, and higher levels of interpersonal confidence than older people who are not involved in political activities [60]. In contrast, losing (or never having had) the personal resources deemed necessary to participate in such activities in terms of health, income, time, and civic skills generates a barrier to both political participation and the continuation of such participation [61].

Participation in political organizations has also been associated with personality factors, such as generativity, a concept coined by Erik Erikson to describe adults' 'concern for establishing and guiding the next generation' [62]. Thus, Serrat, Villar, Warburton, and Petriwskyj [63] found that those who participated in political organizations scored higher than non-participating older people in different aspects of generativity, such as generative concern, generative goals, and perceived cultural demands.

Another group of studies focused on exploring older people's motives for participating in political activities. Such motives can be classified into two basic types: altruistic motives (i.e., aimed at improving some aspect of society or the community) and selfish motives (i.e., aimed at seeking some kind of personal benefit through political participation) [64]. With respect to the first type, research has found that motivations, such as being able to leave a legacy behind [65], mobilizing against injustice [66], and expressing a feeling of responsibility or civic duty [67] are key factors in the decision to become involved in political activities. In terms of the second type, motives, such as a desire to have their opinions taken into account or stay informed [67] and the need to make new friends, stay active, and avoid social isolation [68] were found to be predictors for participation in political activities. On the contrary, a lack of interest, dissatisfaction and indifference in relation to politics were found to be barriers to involvement in political organizations [61].

Finally, opportunities offered by the context include all organizational and sociocultural factors that hamper or prevent older people from getting involved in politics, such as ageist attitudes, tokenism (this include older people in political organizations, but does not consider their opinions in final decisions) and management problems in political organizations [61].

\subsection{Benefits}

There are fewer studies on the benefits of participating in political activities than studies that address the antecedents to participation. However, some have focused on the effects of political activism on variables, such as subjective and psychological well-being and informal learning.

For example, Villar, Celdrán, Fabà, and Serrat [69] compared four active aging activities (caring for grandchildren, caring for dependent relatives, volunteering, and participating in political issues) and found that older people who participate in politics present higher levels of personal satisfaction and fewer aging-related worries than those who did not. In addition, this relationship 
was not present among the older people who performed one of the other active aging activities, such as caring for grandchildren or dependent relatives, and greater personal satisfaction was only seen in the case of older people who carried out voluntary work. More recently, Serrat, Villar, Giuliani, and Zacarés [70] determined that older people who participate in political organizations have higher eudaimonic (which relates to a sense of purpose in life), but not hedonic well-being (which relates to positive emotions), than those who do not. When addressing motivations to participate, it is essential to assume a life-course perspective, as those with a life-story of political commitment are more likely to continue participating with older age [71].

Finally, with respect to informal learning from participation in political activities, research has shown that older people experience a wide range of learning opportunities. These include the acquisition of instrument and political skills and aspects related to improvements in spiritual or personal development $[66,72]$.

\section{Discussion}

This work aimed to analyze the diverse concepts of active aging and to describe and compare three activities commonly associated with an active aging lifestyle in terms of their antecedents and benefits: (1) participation in leisure activities undertaken in senior centers (a self-oriented activity that needs few resources), (2) participation in high-intensity sporting activities (a selforiented activity involving a high level of resources), and (3) participation in political organizations (an other-oriented activity that requires many resources).

Our brief review of each activity suggests that, as expected, antecedent factors, in terms of predictive variables and specific motives to participate, change depending on the type of activity. Thus, activities requiring a high investment of resources seem to be more demanding in terms of previous education and social capital, whereas factors, such as generative-related motives, are particularly important in the other-oriented activities.

Analyzing activities from a life history perspective has been vastly overlooked in studies on active aging. It is likely that examining the extent to which an older person accumulated the necessary resources earlier in life could help determine whether he or she leads an active lifestyle later in life. Recognizing that active aging may be, at least in part, a continuation of one's middleage lifestyle and the result of investments made earlier in life could lead to a more complete understanding of the factors that determine activity patterns in older age.

Considering the benefits of an active lifestyle, regardless of their nature, our study identified features that were common to the three activity types analyzed. Thus, we detected benefits related to health, psychological well-being, and self-esteem and found that social networks provide emotional support and opportunities for developing significant relationships. Such similarities may have been partly favored by the formal nature of the activities, in which formal organizations structure the activities, allocate time, set objectives, and distribute roles. However, beyond such common features, each activity also present a specific set of benefits. For instance, sports are particularly beneficial for health, whereas political activity improve participants' eudaimonic well-being and increase the sense of being useful and making a positive contribution to the community.

These relatively specialized benefits, which were particularly evident in activities that require a high investment in terms of commitment and resources, might also involve some level of risk if the 
person fails or becomes dissatisfied with the activity. For instance, the physical pain and frustration associated with injuries affect people who practice competitive sport, while tokenism and feelings of uselessness may be significant in the case of political participation. The presence of potential negative consequences of active lifestyles in later life, an aspect that the research has so far virtually ignored, is key to ensure that older people continue participating, prevent withdrawals, and maximize the benefits of the activity.

Similarly, a model that includes the antecedents and motivations on one side and the effects and consequences on the other may be particularly limiting when it comes to understanding people's participation in active aging activities. Such a model overlooks the participants' experience, which includes aspects like learning opportunities, a subjective balance between the benefits and costs, and the trade-offs between the different activities and roles in which they may be involved. These aspects determine a person's decision to continue participating, regulate their level of commitment to the activity, and decide to quit.

Including this experience-related dimension in active aging research would lead to a more complete understanding of the complex dynamics involved older adults' participation. In addition, it would provide important practical information for organizations as a means to coordinate activities, thereby improving the management of older people's participation.

\section{Author Contributions}

All authors contributed equally to this work.

\section{Competing Interests}

The authors have declared that no competing interests exist.

\section{References}

1. Villar F. Successful ageing and development: The contribution of generativity in older age. Ageing Soc. 2012; 32: 1087-1105.

2. Walker A. A strategy for active ageing. Int Soc Secur Rev. 2002; 55: 121-139.

3. Fernández-Ballesteros R. Active Aging. The Contribution of Psychology. Göttingen: Hogrefe; 2008.

4. WHO. Active ageing: A policy framework. Geneve: World Health Organization, 2002.

5. Marhánková JH. Seductive solutions, inspiration, easy-to-remember phrases, and ambiguity: Why is the idea of active ageing so successful? In Tomczyk $\measuredangle$, Klimczuk A, Editors. Selected Contemporary Challenges of Ageing Policy. Kraków: Uniwersytet Pedagogiczny w Krakowie; 2017 (7-25).

6. Hamblin KA. Active ageing in the European Union. Policy convergence and divergence. London: Palgrave McMillan; 2013.

7. Foster L, Walker A. Active and successful aging: A European policy perspective. Gerontol. 2015; 55: 83-90.

8. Faber P. Active ageing: A policy framework in response to the longevity revolution. Rio de Janeiro: ILC-Brazil; 2015.

9. Sao Jose JM, Timonen V, Amado CA, Santos SP. A critique of the active ageing index. J Aging 
Stud. 2017; 40: 49-56.

10. Boudiny K, Mortelmans D. A critical perspective: towards a broader understanding of "active ageing". Electronic J Appl Psychol. 2011; 7: 8-14

11. Zaidi A, Gasior K, Zolyomi E, Schmidt A, Rodrigues R, Marin B. Measuring active and healthy ageing in Europe. Journal of Eur Soc Pol. 2017; 27: 138-157.

12. United Nations Economic Commission for Europe (2013). Introducing the Active Ageing Index. Policy brief. Available at https://ec.europa.eu/eip/ageing/library/policy-brief-introducingactive-ageing-index en

13. Caro FG, Caspi E, Burr JA, Mutchler JE. Global activity motivation and activities of older people. Activ Adaptation Aging. 2009; 33: 191-208.

14. Boulton-Lewis GM, Buys L, Lovie-Kitchin J. Learning and active aging. Educ Gerontol. 2006; 32: 271-282.

15. Principi A, Jensen PH, Lamura, G. Active ageing: Voluntary work by older people in Europe. Bristol: The Policy Press; 2014.

16. Serrat R, Villar F, Celdrán M. Factors associated with Spanish older people's membership in political organizations: The role of active aging activities. Eur J Ageing. 2015; 12: 239-247.

17. Burr JA, Mutchler, JE, Caro FG. Productive activity clusters among middle-aged and older adults: Intersecting forms and time commitments. J Gerontol Series B: Psychol Sci Soc Sci. 2007; 62: S267-S275.

18. Villar F, Celdrán M. Generativity in older age: A challenge for universities of the third age (U3A). Educ Gerontol. 2012; 38: 666-677.

19. Boudiny K. 'Active ageing': From empty rhetoric to effective policy tool. Ageing Soc. 2013; 33: 1077-1098.

20. Older Americans Act (2015). Fact Sheet: Senior Centers. Consultado en: https://www.ncoa.org/resources/fact-sheet-senior-centers/

21. Higgins J. Exploring the politics and policy surrounding senior center gambling activities. J Aging Stu. 2005; 19: 85-107.

22. Salari S, Brown, BB, Eaton, J. Conflicts, friendship cliques and territorial displays in senior center environments. J Aging Stud. 2006; 20: 237-252.

23. Wacker RR, Roberto KA. Community resources for older adults community resources for older adults programs and services in an era of change. Thousand Oaks: SAGE; 2014.

24. IMSERSO. El libro blanco del envejecimiento activo [White book on active aging]. Madrid: Instituto de Mayores \& Servicios Sociales, 2011.

25. Ingvaldsen AK, Balandin S. 'If we are going to include them we have to do it before we die': Norwegian seniors' views of including seniors with intellectual disability in senior centres. J Appl Res Intellect Disabil. 2011; 24: 583-593.

26. Townley S, Papaleontiou M, Amanfo L, Henderson CR, Pillemer K, Beissner K, et al. Preparing to implement a self-management program for back pain in New York City senior centers: What do prospective consumers think? Pain Med. 2010: 11: 405-415.

27. McGovern J, Brown D, Gasparro V. Lessons learned from an LGBTQ senior center: A Bronx tale. J Gerontol Soc Work. 2016; 59: 496-511.

28. Fitzpatrick TR, McCabe J. Future challenges for senior center programming to serve younger and more active baby boomers. Activ Adapt Aging. 2008; 2: 198-213.

29. Prieto D, Herranz D, Rodríguez P. Envejecer sin ser mayor. Nuevos Roles en la participación 
social en la edad de la jubilación. Madrid: Fundación Pilares; 2015.

30. Weil J. The new neighborhood senior center: redefining social and service roles for the baby boom generation. New York: Rutgers University Press; 2014.

31. Bobitt JL. Factors impacting the implementation of evidence-based wellness programs in Illinois senior centers. Dissertation Abstr Int: Section B: Sci Engin. 2016; 77.

32. Austin EN, Johnston YAM, Morgan LL. Community gardening in a senior center: a therapeutic intervention to improve the health of older adults. Therapeutic Recreation J. 2006; 40: 48-56.

33. Fulbright $\mathrm{S}$. Rates of depression and participation in senior center activities in communitydwelling older persons. Dissertation Abstr Int Section B: The Sci Engineering. 2010; 70: 5160.

34. Rhynes L, Hayslip B, Caballero D, Ingman, $S$. The beneficial effects of senior center attendance on grandparents raising grandchildren. J of Intergen Relat. 2013; 11: 162-175

35. Aday RH, Kehoe GC, Farney LA. Impact of senior center friendships on aging women who live alone. J Women Aging. 2006; 18: 57-73.

36. Dattilo J, Lorek AE, Mogle J, Sliwinski M, Freed S, Frysinger M, et al. Perceptions of leisure by older adults who attend senior centers. Leisure Sci. 2015; 37: 373-390.

37. Dreibelbis TD, George DR. An intergenerational teaching kitchen: Reimagining a senior center as a shared site for medical students and elders enrolled in a culinary medicine course. J Intergen Relat. 2017; 15: 174-180.

38. Dionigi R, O'Flynn G. Performance discourses and old age: What does it mean to be an older athlete? Sociol Sport J. 2007; 24: 359-377.

39. European Commission (2014). Sport and physical activity. Special Eurobarometer 412, Wave EB80.2. Available at http://ec.europa.eu/commfrontoffice/publicopinion/archives/ebs/ebs 334 en.pdf

40. Heo J, Culp B, Yamada N, Won Y. Promoting successful aging through competitive sports participation: Insights from older adults. Qualit Health Res. 2013; 23: 105-113.

41. Gard M, Dionigi RA, Horton S, Baker J, Weir P, Dionigi C. The normalization of sport for older people? Annals Leisure Res. 2017; 20: 253-272

42. Baert V, Gorus E, Mets T, Geerts C, Bautmans I. Motivators and barriers for physical activity in the oldest old: A systematic review. Ageing Res Rev. 2011; 10: 464-474.

43. Eime R, Young J, Harvey J, Charity M, Payne W. A systematic review of the psychological and social benefits of participation in sport for adults: Informing development of a conceptual model of health through sport. Int J Behav Nutr Phys Activ. 2013; 10: 98-119.

44. Gill DL, Williams L, Dowd DA, Beaudoin CM, Martin JJ. Competitive orientations and motives of adult sport and exercise participation. J Sport Behav. 1996; 19: 307-318.

45. Dionigi RA, Fraser-Thomas J, Logan, J. The nature of family influences on sport participation in Masters athletes. Annals Leisure Res, 2012; 15: 366-388.

46. Martínez del Castillo J, Jiménez-Beatty, JE, Graupera JL, Martín M, Campos A, Del Hierro, D. Being physically active in old age: Relationships with being active earlier in life, social status and agents of socialisation. Ageing Soc. 2010; 30: 1097-1113.

47. Jenkin CR, Eime RM, Westerbeek H, O'Sullivan G, Van Uffelen, JGZ. Sport and ageing: A systematic review of the determinants and trends of participation in sport for older adults. BMC Public Health. 2017; 17. 
48. Lübs L, Peplies J, Drell C, Bammann K. Cross-sectional and longitudinal factors influencing physical activity of 65 to 75-year-olds: a pan European cohort study based on the survey of health, ageing and retirement in Europe (SHARE). BMC Geriatrics. 2018; 18: 94.

49. Pérez M, Gázquez J, Molero M, Mercader I. Un estudio de campo sobre el envejecimiento activo en función de la actividad física y ejercicio físico [A study on active aging depending on phsysical activity and physical exercise]. Rev Iberoamer Psicol Salud. 2012; 3: 19-37.

50. Booth ML, Bauman A, Owen N. Perceived barriers to physical activity among older Australians. J Aging Phys Activ. 2002; 10: 271-280.

51. Tayrose GA, Beutal, BG, Cardone DA, Sherman OH. The masters athlete: A review of current exercise and treatment recommendations. Sports Health. 2015; 7: 270-276.

52. Marques A, Peralta M, Sarmento H, Martins J, González Valeiro M. Associations between vigorous physical activity and chronic diseases in older adults: a study in 13 European countries. Eur J of Public Health. 2018; 28: 850-855.

53. Gayman AM, Fraser-Thomas J, Dionigi RA, Horton S, Baker J. Is sport good for older adults? A systematic review of psychosocial outcomes of older adults' sport participation. Int Rev Sport Exercise Psychol. 2017; 10: 164-185.

54. Baker J, Fraser-Thomas, J, Dionigi R, Horton S. Sport participation and positive development in older persons. Eur Rev Aging Phys Activ. 2010; 7: 3-12.

55. Thompson RJ, Mata J, Jaeggi SM, Buschkuehl M, Jonides J, Gotlib IH. Maladaptive coping, adaptive coping, and depressive symptoms: Variations across age and depressive state. Behav Res Ther. 2010, 48: 459-466.

56. Windle $G$, Hughes $D$, Linck $P$, Russell I, Woods B. Is exercise effective in promoting mental well-being in older age? A systematic review. Aging Ment Health. 2010; 14: 652-669.

57. Liechty T, West S, Naar J, Son J. Perceptions of ageing among older women softball players. Annals Leisure Res. 2017; 20: 295-313.

58. Phoenix C, Tulle E. Physical activity and ageing. In J Piggin, L Mansfeld, M. Weed.The Routledge handbook of physical activity policy and practice. London: Routledge; 2018.

59. Kirby JB, Kluge MA. Going for the gusto: Competing for the first time at age 65. J Aging Phys Activ. 2013; 21: 290-308.

60. Nygard M, Nyqvist F, Steenbeek W, Jakobsson G. Does social capital enhance political participation of older adults? A multi-level analysis of older Finns and Swedes. J Int Compar Soc Pol. 2015; 31: 234-254.

61. Serrat R, Petriwskyj A, Villar F, Warburton J. Barriers to the retention of older participants in political organisations: Evidence from Spain. Ageing \& Soc. 2017; 37: 581-606.

62. Erikson E. Childhood and society. New York: Norton; 1963.

63. Serrat R, Villar F, Warburton J, Petriwskyj A. Generativity and political participation in old age: A mixed method study of Spanish elders involved in political organisations. J Adult Dev. 2017: 24: 163-176.

64. Serrat R, Villar F. Older people's motivations to engage in political organizations: Evidence from a catalan study. VOLUNTAS: Int J Volunt Nonprofit Org. 2016; 27: 1385-1402.

65. Fox J, Quinn S. The meaning of social activism to older adults in Ireland. J Occup Sci. 2012; 19 : 358-370.

66. Narushima M. A gaggle of raging grannies: The empowerment of older Canadian women through social activism. Int J Lifelong Edu. 2004; 23: 23-42. 
67. Petriwskyj A, Warburton J, Everingham J, Cuthill M. Seniors' motivations for participation in local governance: Evidence from an Australian study. Loc Gov Stud. 2014; 40: 240-263.

68. Barnes M, Harrison E, Murray L. Ageing activists: Who gets involved in older people's forums? Ageing Soc. 2011; 32: 261-280.

69. Villar F, Celdrán M, Fabà J, Serrat R. La generatividad en la vejez: Extensión \& perfil de las actividades generativas en una muestra representativa de personas mayores españolas [Generativity in older age: Extension and generative activities profile in a representative simple of Spanish older people]. Rev Ibero-Amer Gerontol. 2013; 1: 61-79.

70. Serrat R, Villar F, Giuliani, M, Zacarés J. Older people's participation in political organizations: The role of generativity and its impact on well-being. Educ Gerontol. 2017; 43: 128-138.

71. Nolas SM, Varvantakis C, Aruldoss V. Political activism across the life course. Contemporary Soc Sci. 2017: 12: 1-12.

72. Serrat R, Petriwskyj A, Villar F, Warburton J. Learning through political participation: A case study of Spanish elders involved in political organizations. Adult Educ Quart. 2016; DOI $10.1177 / 0741713615627013$.

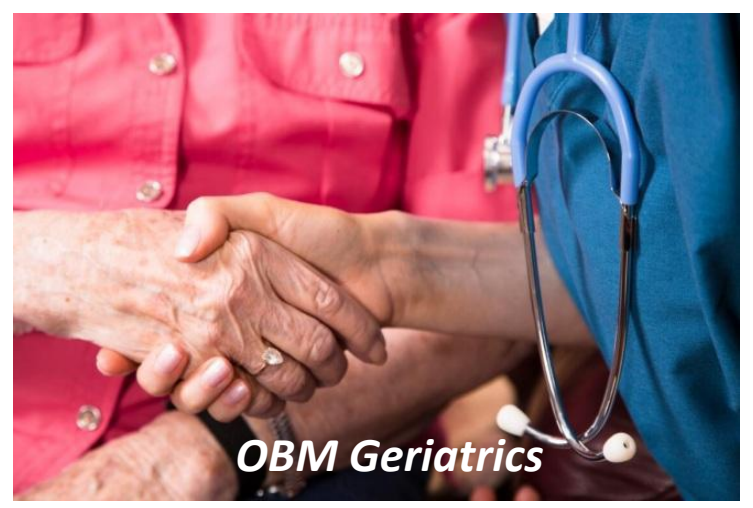

Enjoy OBM Geriatrics by:

1. Submitting a manuscript

2. Joining in volunteer reviewer bank

3. Joining Editorial Board

4. Guest editing a special issue

For more details, please visit: http://www.lidsen.com/journals/geriatrics 